\title{
Research on the effect of cooperative learning model on nursing skills of practice nurses and standardized training of newly-recruited nurses.
}

\author{
Li Yang ${ }^{1}$, Donghua Jiang1, Hanzhu Nie ${ }^{2 *}$, Siyuan Tang ${ }^{3}$ \\ ${ }^{1}$ Department of Nursing, Changde Vocational Technical College, PR China \\ ${ }^{2}$ Department of Nursing, No.1 Traditional Chinese Medicine Hospital in Changde, PR China \\ ${ }^{3}$ Central South University, Xiang Ya Nursing School, PR China
}

\begin{abstract}
Objective: To investigate the value of cooperative learning model in the nursing skills of practice nurses and standardized training for newly-recruited nurses.

Methods: 130 practice nurses and 80 newly-recruited nurses from two Grade-three hospitals in Hunan Province were selected as objects of study, and randomly divided into two groups. The practice nurses and newly-recruited nurses in control group received traditional clinical nursing teaching and training, and those in intervention group receive clinical nursing teaching and training under cooperative learning model, the score, self-learning ability and patient satisfaction in the two groups were compared. Results: After 1 month of learning, the theoretical scores and skill scores of practice nurses and newlyrecruited nurses in intervention group were significantly higher than those in control group $(P<0.05)$. The practice nurses and newly-recruited nurses in intervention group recognized that the training model improved their learning initiative, awareness of cooperation, ability to think, communication skills and comprehensive ability compared with those in control group $(\mathbf{P}<0.05)$.

Conclusion: Cooperative learning model can improve the effectiveness of training for practice nurses and newly-recruited nurses, which not only promotes nurses' theoretical knowledge and nursing skills, but also trains the ability of cooperation, thinking and communication, so it is conducive to practice nurses and newly-recruited nurses in the new post.
\end{abstract}

Keywords: Cooperative learning model, Practice nurses, Newly-recruited nurses, Standardized training, Nursing skills. Accepted on December 30, 2017

\section{Introduction}

Practice nurses have a lack of nursing skills, emergency capacity, functional experience, etc., from the school to the new job in hospital [1], combined with patients with complex and serious diseases and a variety of complex operating equipment, causing greater psychological pressure. Most of the newly-recruited nurses are those without work experience, and act as the fresh troops of clinical nursing, but the lack of social and clinical nursing experience will affect the quality of nursing, so the standardized pre-service training is important to ensure the quality and safety of nursing [2,3]. Cooperative learning model refers to the learning activity with group as a unit to maximize the learning effect. With the development of nursing demonstration projects, traditional one-to-one followup practice nurses and newly-recruited nurses cannot meet the demand, and hospitals are also constantly improving the nursing teaching method [4]. This research aims to investigate the application value of cooperative learning model. It is now reported as follows.

\section{Data and Methods}

\section{Baseline data}

A total of 130 practice nurses from two Grade-three hospitals in Hunan Province in May 2016 were selected, and 80 newlyrecruited nurses were selected. The practice nurses are all junior students in nursing specialty in institutions of higher education. They were randomly divided into two groups. The control group included 65 practice nurses, including 5 males and 60 females aged 19-24 years with an average of (20.76 \pm 0.32 ) years; 40 newly-recruited nurses, including 4 males and 36 females aged 21-26 years with an average of $(23.40 \pm 0.28)$ years; 34 nurses had no working experience and 6 nurses had working experience. The intervention group included 65 practice nurses, including 8 males and 57 females aged 18-24 years with an average of $(20.70 \pm 0.35)$ years; 40 newlyrecruited nurses, including 3 males and 37 females with an average of $(23.51 \pm 0.25)$ years; 35 nurses had no working experience and 5 nurses had working experience. There were no significant difference in the baseline data between practice 
nurses and newly-recruited nurses in the two groups $(\mathrm{P}>0.05)$, and data were comparable.

\section{Methods}

The control group received traditional clinical nursing teaching and training: practice nurses were given three basic training manuals, clinical practice manuals, specialist nursing practices, nursing skills assessment standards and other professional teaching materials through classroom demonstrations, role play, discussion and clinical nursing demonstration. The newly-recruited nurses, on the one hand, were given training programs and assessment standards; on the other hand, they received unified demonstration teaching in the first week, and practiced and self-taught in the second and third weeks, followed by examination in the fourth week. Intervention group received the training in cooperative learning mode: (1) grouping. According to the heterogeneity within the group and the homogeneity between groups, nurses were randomly divided into practice nurses or newly-recruited nurses into groups with 4-6 members, and then the team members selected a team leader. In grouping, the personality, learning ability, age, nursing skills and other factors of each practice nurses or newly-recruited nurses should be considered, the strength of each group should be equal and the group members should cooperate with each other. The group received the teaching about nursing skills, theoretical knowledge, rules and regulations. (2) Learning within group. 1) Learning under leader. Teachers give a brief introduction of knowledge points first, and then each group members learn under the leadership of leader, discuss the specific steps of nursing operations, precautions, etc., and explain to each other to deepen the memory through questions. For example, for the newlyrecruited nurses, the learning content in the first week mainly includes the rules and regulations, nursing duties, environment, norms and job skills training in hospitals, and the group members should discuss and study with each other. 2) Role play. In view of the specific content of nursing operation, the nurse should be guided by the teacher first. Then the group members should play the role of each other and evaluate each other, and the teachers should review and focus on the common problems. For example, in case of a specific emergency care and treatment, nurses are assigned to different positions, and teachers act as emergency doctors, and nurses cooperate with doctors to open venous access, cardiac pressure, connect ECG monitor, ask about the medical history and record, and execute the doctor's advice. Nurses change the roles for mutual supervising and learning, while they also observe the role playing of other groups and discuss with each other. 3) Nursing skill examination. Individual assessment and team assessment are regularly combined, and the necessary nursing skills were randomly selected for assessment for each member in the group, and teachers focus on comments and point out the problems, and score in accordance with the relevant assessment standards, so that each nurse can understand the shortcomings of their own practical skills, correct mistakes and improve the level of practical skills with the help of teachers. 4) Group discussion. In view of the content of training, the group discussion activity is conducted once a week. Teachers give learning tasks in advance. The group members collect information, make plans and discuss with each other after class. Finally, the representative from each group speaks and exchange with each other, while teachers assist and guide the discussion. For example, in view of the nurse-patient communication, each group collects the authoritative literature, observes and inquires about the language and behavior of nurses in nurse-patient communication, summarizes the discussions within the group, draws conclusions and complements each other in the discussion; moreover, various factors to be considered in nurse-patient communication and conducting nurse-patient communication practice should also be mastered.

\section{Assessment}

The learning effects in the two groups of nurses were evaluated via theory test and skill assessment before learning and at one month after learning. The theory test was designed based on the examination outline of nurse qualification examination with a total of 100 points. Skill assessment was based on the content of learning, which evaluated the nursing skill operation from several nursing skills with a total of 100 points. Selfmade questionnaire survey was used for the nurses' satisfaction with training model: improve the learning initiative, improve the awareness of cooperation, improve the ability to think, improve communication skills, and improve the comprehensive ability.

\section{Statistical methods}

SPSS17.0 software was used for comparison of measurement data, and $\mathrm{t}$ test was used. Chi-square test was used for comparison of enumeration data. $\mathrm{P}<0.05$ suggested that the difference was statistically significant.

\section{Results}

Comparison of examination results before and after learning is shown in Table 1.

Table 1. Examination results of the two groups of nurses before and after learning.

\begin{tabular}{llcc}
\hline \multirow{2}{*}{ Group } & \multicolumn{2}{c}{ Theory score } & Skill assessment \\
\cline { 2 - 3 } & Before learning & 1 month after learning & Before learning \\
\hline
\end{tabular}

Intervention group 
Research on the effect of cooperative learning model on nursing skills of practice nurses and standardized training of newly-recruited nurses

\begin{tabular}{lllll}
\hline Practice nurses & $74.3 \pm 2.6$ & $92.3 \pm 4.1^{\#^{*}}$ & $78.2 \pm 3.1$ & $91.4 \pm 4.5^{\#^{*}}$ \\
\hline Newly-recruited nurses & $81.3 \pm 2.4$ & $95.8 \pm 4.5^{\#^{*}}$ & $83.5 \pm 3.0$ & $94.5 \pm 4.2^{\#^{*}}$ \\
\hline Control group & & & & \\
\hline Practice nurses & $74.7 \pm 2.5$ & $86.4 \pm 3.8^{\#}$ & $78.5 \pm 3.3$ & $85.1 \pm 3.5^{\#}$ \\
\hline Newly-recruited nurses & $81.6 \pm 2.7$ & $88.9 \pm 4.2^{\#}$ & $84.1 \pm 3.5$ & $87.9 \pm 3.7^{\#}$ \\
\hline
\end{tabular}

Note: intergroup comparison ${ }^{*} \mathrm{P}<0.05$; intragroup comparison before and after learning ${ }^{\#} \mathrm{P}<0.05$.

Nurses' satisfaction with the training model is shown in Table

2.

Table 2. Satisfaction with learning model of the two groups of nurses.

\begin{tabular}{|c|c|c|c|c|c|}
\hline Group & $\begin{array}{l}\text { Improve } \\
\text { learning }\end{array}$ & $\begin{array}{l}\text { Improve awareness } \\
\text { collaboration }\end{array}$ & of Improve ability to think & $\begin{array}{l}\text { Improve } \\
\text { skills }\end{array}$ & Improve overall ability \\
\hline \multicolumn{6}{|l|}{ Intervention group } \\
\hline Practice nurses & $59(90.77)^{*}$ & $55(84.62)^{*}$ & $57(87.69)^{*}$ & $61(93.85)^{*}$ & $56(86.15)^{*}$ \\
\hline Newly-recruited nurses & $38(95.0)^{*}$ & $37(92.5)^{*}$ & $35(87.5)^{*}$ & $37(92.5)^{*}$ & $35(87.5)^{*}$ \\
\hline \multicolumn{6}{|l|}{ Control group } \\
\hline Practice nurses & $48(73.85)$ & $45(69.23)$ & $48(73.85)$ & $51(78.46)$ & $46(70.77)$ \\
\hline Newly-recruited nurses & $30(75.0)$ & $27(67.5)$ & $25(62.5)$ & $26(65.0)$ & $24(60.0)$ \\
\hline
\end{tabular}

\section{Discussion}

\section{Cooperative learning model improves the efficiency of training}

Cooperative learning model strengthens mutual learning among members of group, forming a mutual help atmosphere in a short period of time, and members improve and correct incorrect operation with the help of each other, thus reducing the burden of teachers and improving the training efficiency $[5,6]$. Also, it improves self-learning ability and communication skills of practice nurses and newly-recruited nurses.

\section{Improve the theoretical level and nursing skills}

Cooperative learning model emphasizes the mutual help, mutual supervision and mutual learning among one another. Under the influence and help of people, nurses improve their interest in learning and find a suitable learning method, achieving significant learning effects [7]. Teachers act as guide to create a good and harmonious learning environment and propose clear learning plan and goals for students, etc. Under cooperative learning model, students guide and supervise one another, and encourage students to learn, practice and summarize through group discussions, role-playing and other learning activities, so as to improve their mastery of theoretical knowledge and nursing skills $[8,9]$. The results showed that the theoretical score and skill assessment of practice nurses and newly-recruited nurses in intervention group were higher than those in control group.

\section{Cultivate the comprehensive ability of trainees}

The results of this study showed that practice nurses and newly-recruited nurses in intervention group have a significantly higher acceptance rate of training model and believe that the cooperative learning mode is conducive to improving the learning initiative, cooperation awareness, thinking ability, communication skills and comprehensive ability. Under the cooperative learning environment, members get along well with and help each other [10]. For example, introverted students continue to exercise courage and cultivate outgoing personality through discussions in the group and competitive learning activities among the groups. Group discussion enables students to learn from one another, improve the learning initiative and develop critical thinking habits, learn from each other in mutual emulation, improve their learning competitiveness and comprehensive ability.

In conclusion, the cooperative learning model used in nursing skills training for practice nurse and standardized training for newly-recruited nurses is conducive to improving training efficiency, promoting the training of theoretical knowledge and nursing ability, thus providing a good way for nurses in new jobs. 


\section{Funding}

1. 2016 year Hunan province occupation education and teaching reform project "Application Research of Group Cooperative Learning Based on Microcosmic in Clinical Practice of Nursing Students in Higher Vocational Schools" (ZJGB2016125)

2. 2017 Hunan Provincial Department of Education general scientific research projects "Application Research and Demonstration of Cooperative Learning Strategies in Clinical Nursing Teaching" (17C0212)

3. 2016 Changde City Science and Technology Development Project special research general project "Application of Cooperative Learning in Clinical Nursing Teaching" (2016KZ30)

\section{References}

1. Irvine AB, Beaty JA, Seeley JR. Use of a dementia training designed for nurse aides to train other staff. J Appl Gerontol 2013; 32: 936-951.

2. Osborne K. Cut agency staff and use money to train nurses, says think tank. Nursing Standard 2015; 29: 11-11.

3. Curtis JR, Back AL, Ford DW. Effect of communication skills training for residents and nurse practitioners on quality of communication with patients with serious illness: A randomized trial. Am J Med Assoc 2013; 310: 2271-2281.

4. Irvine $\mathrm{AB}$, Billow $\mathrm{MB}$, Mcmahon E. Mental illness training on the Internet for nurse aides: A replication study. J Psychiatric Mental Health Nursing 2013; 20: 902-912.
5. Brunetto Y, Farr-Wharton R, Shacklock K. Communication, training, well-being, and commitment across nurse generations. Nursing Outlook 2012; 60: 7-15.

6. Roussou E, Iacovou C, Georgiou L. Development of a structured on-site nursing program for training nurse specialists in rheumatology. Rheumatol Int 2012; 32: 1685-1690.

7. Kelly LA, Wicker TL, Gerkin RD. The relationship of training and education to leadership practices in frontline nurse leaders. J Nursing Admin 2014; 44: 158-163.

8. Flurry M, Brooke S, Micholetti B. Nurse training with simulation: An innovative approach to teach complex microsurgery patient care. Annal Plastic Surg 2012; 69: 459-461.

9. Henoch I, Danielson E, Strang S. Training intervention for health care staff in the provision of existential support to patients with cancer: A randomized, controlled study. J Pain Symptom Management 2013; 46: 785-794.

10. Boss RD, Urban A, Barnett MD. Neonatal critical care communication (NC3): Training NICU physicians and nurse practitioners. J Perinatol 2013; 33: 642-646.

\section{*Correspondence to}

Hanzhu Nie

Department of Nursing

No.1 Traditional Chinese Medicine Hospital in Changde

PR China 